\title{
RESEARCH OF THE BIOSTABILITY OF ORGANIC BASES OF PAINTS FOR WOOD
}

\author{
Sergii Guzii $\bowtie$ \\ Department of Physics and Chemistry of Polymers \\ Institute of Macromolecular Chemistry of the National Academy of Sciences of Ukraine \\ 48 Kharkivske highway, Kyiv, Ukraine, 02160 \\ sguziy2@gmail.com \\ Ihar Bazhelka \\ Department of Woodworking Technology ${ }^{1}$ \\ Anastasiya Kanavalava \\ Department of Woodworking Technology ${ }^{1}$ \\ ${ }^{1}$ Belarusian State Technological University \\ 13 a Sverdlova str., Minsk, Republic of Belarus, 220006
}

$\triangle$ Corresponding author

\begin{abstract}
The biostability of organic film-formers of paints and varnishes intended for staining wood to the action of the fungus Aspergillus niger was studied. It was found that in Sabouraud's environment on days 7, 14 and 21 from the beginning of infection, the epoxy hardener is characterized by the minimum level of damage, respectively, 1, 1.6 and 2.4 points; alkyd film former has 2 points, and in subsequent time intervals 3.7 points; epoxy resin on day 7 is characterized by a lesion level of 1.7 points, on the following days of exposure - 4 points; pentaphthalic film former, respectively, 2.7, 3.7 and 4 points. According to the degree of resistance in the Sabouraud environment, organic film-formers of wood paints can be ranked as follows: epoxy (hardener) $>$ alkyd $>$ epoxy resin $>$ pentaphthalic >organosilicon. It is shown that in the environment of Czapek on 7, 14 and 21 days from the beginning of infection, the minimum level of damage is characterized by an epoxy hardener, respectively, 2, 2.3 and 3 points; pentaphthalic film former, respectively, 2 and 3 points; alkyd film former, respectively, 2.4, 3.7 and 4 points; epoxy resin on day 7 is characterized by a lesion level of 3 points, on the following days of exposure -4 points. According to the degree of resistance in the environment of Czapek, organic film-forming agents for wood paints can be ranked as follows: epoxy (hardener) $>$ pentaphthalic $>$ alkyd $>$ epoxy resin $>$ organosilicon. Organosilicon film-formers were most intensively affected by the fungus both 7 days after exposure and at a later time, reaching the maximum values of the lesions - 4 points. During the test period, no zones of mycelium growth inhibition were observed in the studied organic bases.

Keywords: biostability, organic film formers, Sabouraud and Czapek media, Aspergillus niger, wood.
\end{abstract}

DOI: $10.21303 / 2461-4262.2021 .002142$

\section{Introduction}

The main factors causing biological damage to wood are the microscopic fungi growing on wood and the insects. In temperate latitudes, fungal lesions account for about $90 \%$ of all wood bio-damage $[1,2]$. Biological damage to wood occurs mainly as a result of the use of cellulose, lignin and other wood components by fungi and insects as a source of nutrition $[3,4]$. Bacteria, in comparison to fungi and insects which directly destroy the wood fibers, cause less damage and have an indirect damage effect.

Among the fungi that cause biological damage to wood, there are three main groups: fungi of surface mold (mold-like); wood-coloring; wood-destroying. The greatest damage to wood is caused by wood-destroying fungi. Kthese include fungi of the genera Scrpula, Coriolus, Fomitopsis, Serpula, Chaetomium, etc. [4]. Wood-destroying fungi destroy the structural components - the cell walls of wood. They affect living wood, wet and dump wooden materials and products made from them.

According to [5, 6], paints and varnishes and coatings can undergo microbiological damage in conditions favorable for the development and growth of molds, bacteria and other microorganisms. Typical signs of their manifestation are gray-green, dark spots, molds, bacterial mucus on painted surfaces. This is especially noticeable in places with high humidity. As a result of such lesions, 
cracking, peeling, flaking, the formation of tubercles and holes are noticeable on the surface of the paintwork material [7].

Microscopic fungi, as well as hydrocarbon-oxidizing and sulfate-reducing microorganisms, play an important role in the processes of biocorrosion of paint-and-varnish coatings [8]. Fungi that destroy polymers produce a complex of amino acids, organic acids and a number of enzymes that act on the substrate; cellulose-destroying fungi are especially active against polymer materials. Bacterial lesions are less common and appear as a colorless or colored mucosal plaque. Among the microorganisms affecting (that damage) the varnish-and-paint coatings (VPCs), fungi of the genera Aspergillus, Penicillum, Fusarium, Trichoderma, Alternaria, Cephalosponum, Pullularia, and bacteria of the genera Pseudomonas, Flavobacterium, are often found. The species composition of fungi that damage the VPMs is specific for different soil climatic zones. It is formed from the species that make up the community that is characteristic of the soils of a particular zone [8, 9].

The development of fungi on paintwork occurs either due to the use of the components that make up the coating, or due to substances that contaminate the surface of the paintwork. The destruction of paintwork is carried out as a result of the mechanical action of the mycelium of molds on the coating and under the influence of metabolites secreted by micromycetes in the course of their vital activity (organic acids, amino acids, enzymes, etc.) [10, 11]. The latter cause a decrease in the physical and mechanical properties of the paintwork, such as the modulus of elasticity, tensile stresses and elongation at break. Cracks, peeling, swelling of the paintwork can be caused by microorganisms on the surface or under the paintwork film. The growth of fungi and their development under the film is accompanied by gas formation and an increase in pressure sufficient for peeling and swelling of the paintwork $[12,13]$.

Film-forming substances determine the biostability of paintwork materials and protective coatings based on them. The decisive factor of biostability is the chemical structure of the polymer film-former and the manifestation of its properties in the uncured and in the hardened state. A relationship has been established between the chemical structure of the used film-formers and the growth rate of a number of common fungal strains [14].

Among the studied film-forming substances, the synthetic film-forming polymers demonstrate the best biostability. The fungal resistance of these coatings decreases in the following order: epoxy, polyurethane, melamine-alkyd, organosilicon, pentaphthalic $[15,16]$. An increase in the hardening rate of the film-forming substance, and a decrease in water absorption, roughness and porosity of the film, facilitate an increase in fungal resistance. Smooth, shiny and even films are more biostable due to the fact that fungal spores are more difficult to adsorb on them, thus they become less contaminated.

Most of the well-known works in this direction have a biochemical orientation, therefore, in our opinion, our relevance has a practical orientation and consists in studying the biostability of organic bases of wood paints for their resistance to the effects of contaminated wood with wood destructive fungi.

From the analysis of literary sources, no studies on the selected research problem have been identified.

The aim of research is to determine the resistance of organic paint bases when dyeing wood and products based on it, infected with the fungus Aspergillus niger.

The objectives of research are to determine the level of damage and zones of growth inhibition of the mycelium of the fungus Aspergillus niger in the nutrient media of Sabouraud and Czapek organic bases of paints in the period of 7, 14 and 21 days from the moment of infection.

\section{Materials and methods of research}

Industrial paints were used as starting materials for painting wooden products and structures. The following paints were studied:

a) based on polymer film formers - two-component epoxy paint ADLER-WARK Lackfabrik (Germany);

b) alkyd enamel PF-115P «Polisan» (Ukraine);

c) pentaphthalic enamel Silica, modified with silicone;

d) organosilicon enamel KO-814K «Korona-2000» (Ukraine). 
Out of the variety of methods for assessing biostability [17, 18], VPMs were studied in accordance with the requirements of the standards DSTU EN 15457:2015 [REF] (EN 15457:2014, IDT), ISO/IEC 17025:2017 [REF] and DSTU EN 1275: 2004 [REF] (EN 1275: 1997, IDT). Procedure for performing an experiment to determine biostability:

1) samples of coating materials were selected in accordance with the standard EN ISO 1513 [REF];

2) to check the contamination, the samples of coating materials were placed in Petri dishes with Czapek and Sabouraud media for 5 days at a temperature of $23 \pm 2{ }^{\circ} \mathrm{C}$ and relative humidity of $50 \pm 5 \%$ according to EN 23270 [REF]. The result of contamination is that the samples of the coating materials are not infected by pathogenic flora and fungi;

3) 6 discs of filter paper with a diameter of $55 \mathrm{~mm}$ are prepared for each paint sample. Prior to application, the discs were sterilized with gamma radiation $>10 \mathrm{kGy}$;

4) Czapek and Sabouraud media were placed in the prepared and sterilized (see above) Petri dishes, 3 for each. Composition of nutrient media for microbiological analysis: potato-glucose agarPGA (g/L): potatoes - 200.0; glucose - 20.0; agar-agar - 20.0; distilled water (Czapek-Dox medium with agar (g/L): $\mathrm{KH}_{2} \mathrm{PO}_{4}-0.7 ; \mathrm{K}_{2} \mathrm{HPO}_{4}-0.3 ; \mathrm{MgSO}_{4} \cdot 7 \mathrm{H}_{2} \mathrm{O}-0.5 ; \mathrm{NaNO}_{3}-2.0 ; \mathrm{KCl}-0.5$; $\mathrm{FeSO}_{4} \cdot 7 \mathrm{H}_{2} \mathrm{O}-0.01$; sucrose -30.0 ; distilled water; Sabouraud medium $(\mathrm{g} / \mathrm{L})$ : glucose - 40.0; peptones - 10.0; agar-agar - 20.0; distilled water);

5) a test was performed for sowing mold cultures of Aspergillus niger in Wort agar $6 \% \mathrm{Ba}-$ linga and Chaetómium globósum in PGA with filter paper at a temperature of $24 \pm 2{ }^{\circ} \mathrm{C}$ for 7 days; result - Aspergillus niger sprouted, Chaetómium globósum did not sprout;

6) a suspension of spores of Aspergillus niger with a concentration of $10^{6} \mathrm{spores} / \mathrm{mL}$ was prepared;

7) Petri dishes were contaminated with the medium in which the pain samples applied to the filter paper were located. 3 drops were applied to the disc and 3 to the medium, approximately $0.5 \times 10^{6}$ spores per dish;

8) Petri dishes with samples were placed in a thermostat with a temperature of $24 \pm 2{ }^{\circ} \mathrm{C}$ for 21 days;

9) fixation of the changes was performed on 7, 14, and 21 days of testing;

10) the assessment of the degree of damage was determined in points, according to the requirements of the standard: the ratio of the level of contamination to the points: $0 \%-0$; up to $10 \%-1$; from 10 to $30 \%-2$; from 30 to $50 \%-3$ and from $50 \%-4$.

\section{Results and discussion}

Considering the fact that the coloring of products made from substandard and partially contaminated pine wood, it is advisable to study the resistance of organic paint bases to the influence of the mold fungus Aspergillus niger.

Fig. 1-4 shows photographs of the growth zones of the mycelium of the fungus Aspergillus niger in culture media of Czapek and Sabouraud on organic paint bases on days 7, 14 and 21 from the beginning of contamination.

Fig. 5, 6 show the levels of contamination by the mycelium of the fungus Aspergillus niger on organic bases of paints 7, 14 and 21 days from the beginning of infection.

On the $7^{\text {th }}$ day of the test, the growth of the mycelium of the fungus Aspergillus niger in the resin (Fig. 1, a). In the Sabouraud and Czapek media, the lesion level reaches 1.7 and 3 points, respectively (Fig. 5, 6).

The hardener is affected up to 1 and 2 points in the Sabouraud and Czapek media, respectively (Fig. 5, 6). There were no growth delay zones of the fungus mycelium. Apparently, the hardener contains compounds that inhibit mycelium growth in both media by 1.85 times, compared to resin. In the alkyd film former, compared to the epoxy film former, on the $7^{\text {th }}$ day from the moment of infection, there is an increase by 1.8 times and a decrease by 1.3 times in the average lesion level in the Sabouraud and Czapek medium, respectively (Fig. 2, $\boldsymbol{a}, \mathbf{5}, \mathbf{6}$ ).

In the paint on the pentaphthalic film former on the $7^{\text {th }}$ day from the beginning of the infection, there is an increase in the level of damage in the Sabouraud medium by 1.6 times compared 
to resin, and by 1.4 times compared to the alkyd film former (Fig. 3, a, 5). The organosilicon film former, regardless of the media, already has the highest infection level score on the $7^{\text {th }}$ day from the beginning of the infection -4 (Fig. $4, a)$. This trend is observed both on the $14^{\text {th }}$ and $21^{\text {st }}$ day (Fig. $\left.4, \boldsymbol{b}, \boldsymbol{c}, \mathbf{5}, \mathbf{6}\right)$.
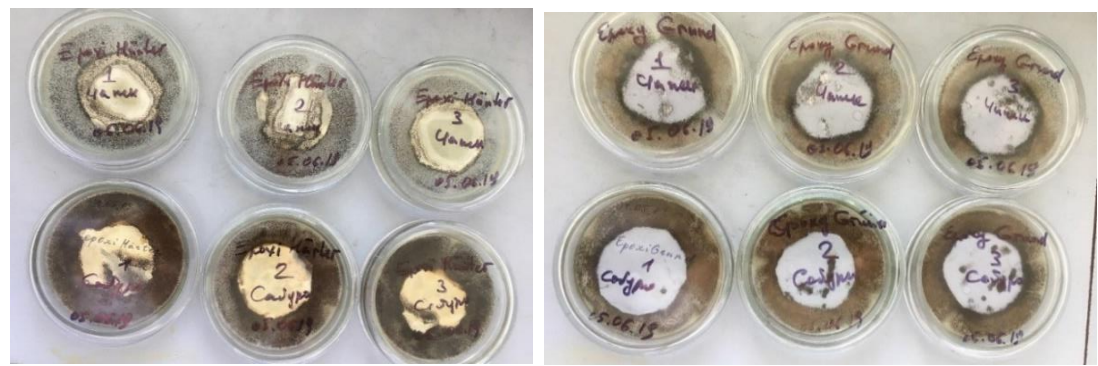

$a$
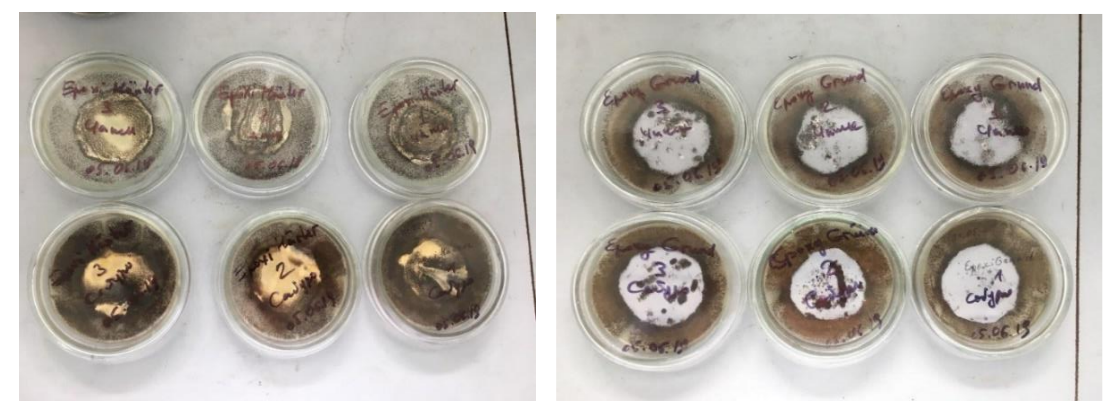

$b$
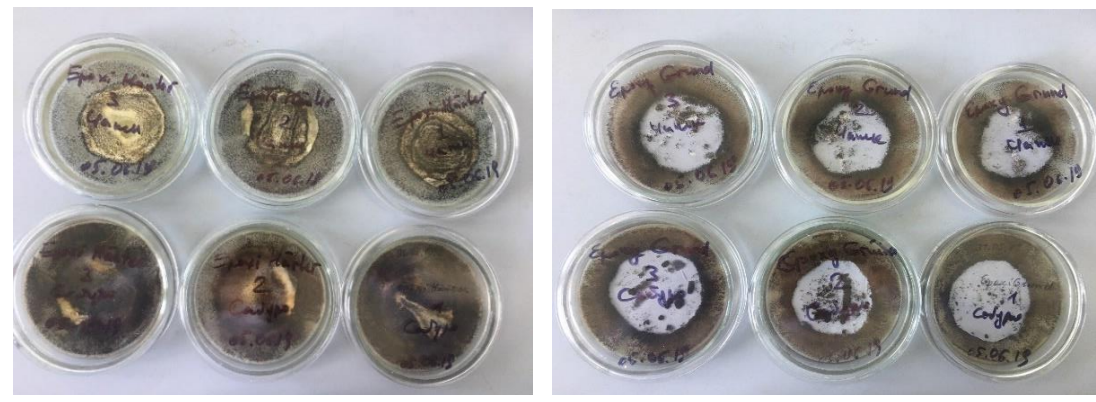

Fig. 1. Zones of growth of the fungus Aspergillus niger in nutrient media Czapek (top) and Sabouraud (bottom) from the beginning of contamination of epoxy film former, days: $a-7 ; b-14 ; c-21$; on the left - resin; on the right - hardener

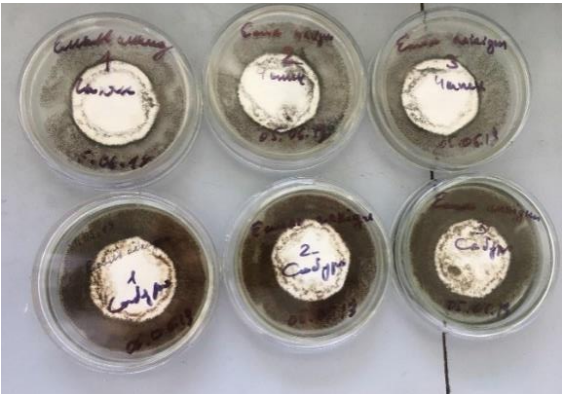

$a$

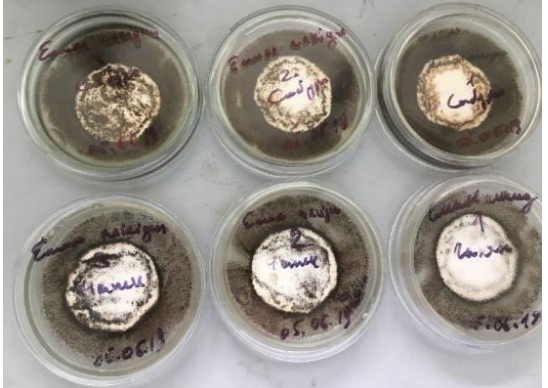

$b$

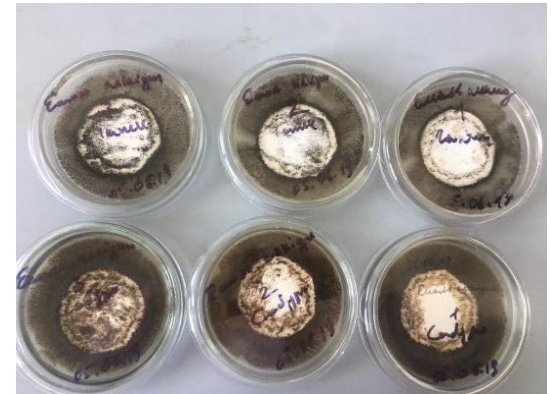

Fig. 2. Zones of growth of the fungus Aspergillus niger in nutrient media Czapek (top) and Sabouraud (bottom) from the beginning of contamination of alkyd film former, days:

$$
a-7 ; b-14: c-21
$$


The level of growth delay of the mycelium of the fungus Aspergillus niger was not detected. In comparison to the previous film formers, the infection of the organosilicon one occurs 1.52 times more intensively.

After 14 days from the beginning of the infection, the resin film former (Fig. 1, $\boldsymbol{b}, \mathbf{5}, \mathbf{6})$ became completely infected by the mycelium of the fungus in both the Sabouraud and Czapek media. The lesion level is 4 points. During the same period, the hardener (Fig. 1, b) in the Sabouraud medium exhibits greater resistance to lesion (damage) by the mycelium of the fungus Aspergillus niger (Fig. 5, 6).

In the Czapek medium, the lesion level of risen is 2.3 points, which is $1.2-1.7$ times higher compared to 7 days after the beginning of infection.

In the case of the alkyd film former on the $14^{\text {th }}$ day in the Sabouraud and Czapek media, the lesion levels increase (Fig. 2, b). The values reach up to 3.7 points, which is $1.61-1.85$ times higher compared to the previous period (Fig. 2, $\boldsymbol{a}, \mathbf{5}, \mathbf{6}$ ). No mycelial growth delay zones were observed in both media.

In the pentaphthalic film former of the paint Silica, modified with silicone, on the $14^{\text {th }}$ day from the moment of infection, an increase in the damage of the paint by the mycelium of the fungus is noted. The level of lesion in the Sabouraud medium is up to 3.7 points, and in the Czapek medium up to 3 points (Fig. 3, b, 5, 6). These values of lesion levels are 1.37-1.5 times higher compared to the samples aged for 7 days (Fig. 3, $\boldsymbol{a}$ ).

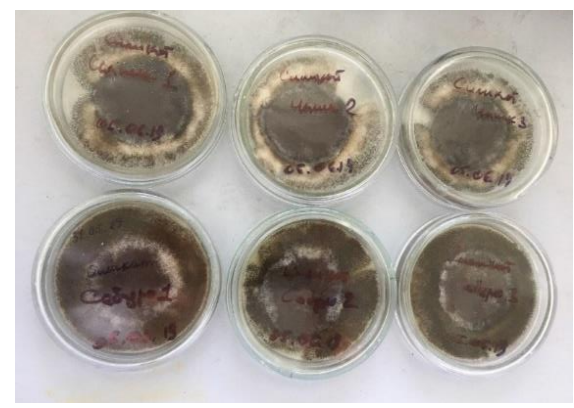

$a$

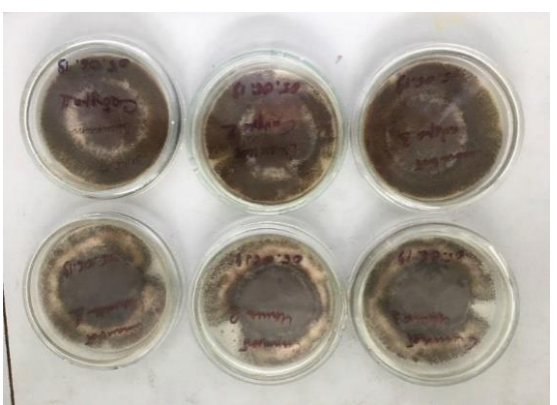

$b$

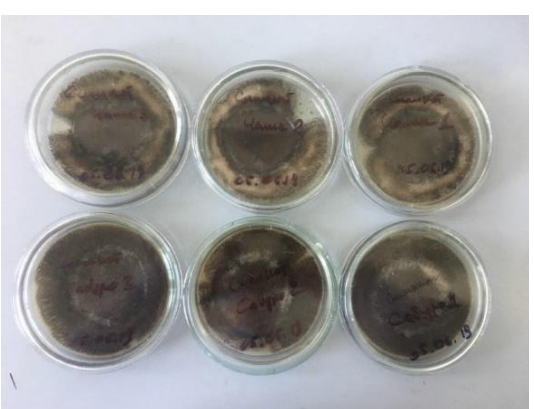

$c$

Fig. 3. Zones of growth of the fungus Aspergillus niger in nutrient media Czapek (top) and Sabouraud (bottom) from the beginning of contamination of pentaphthalic film former, days: $a-7 ; b-14: c-21$

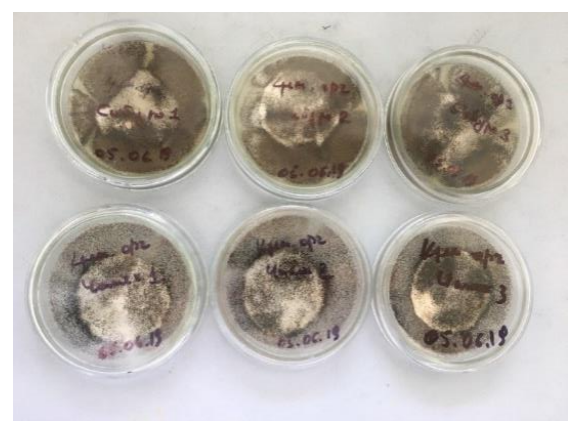

$a$

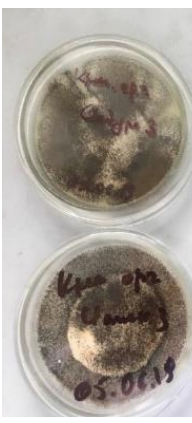

Fig. 4.

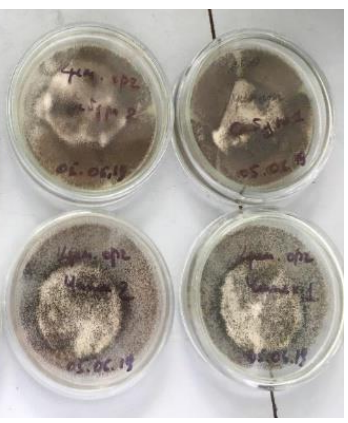

$b$

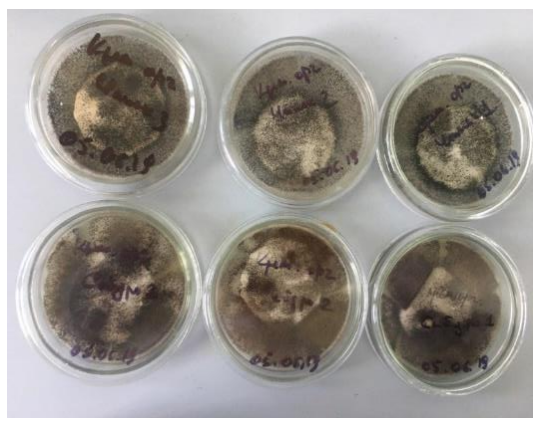

$c$ and Sabouraud (bottom) from the beginning of contamination of organosilicon film former, days:

$$
a-7 ; b-14: c-21
$$

On the $14^{\text {th }}$ day from the moment of infection, the organosilicon film former of the $\mathrm{KO}-814 \mathrm{~K}$ paint is completely infected. The lesion level is maximum, the value of which is 4 points (Fig. $\mathbf{4}, \boldsymbol{b}, \mathbf{5}, \mathbf{6})$. No zones of mycelial growth delay were noted. 
After 21 days from the beginning of infection, the risen film former Eposi Harter (Fig. 1, c) was completely infected with the mycelium of the fungus both in Sabouraud and Czapek media. The lesion level is 4 points. The lesion level of the hardener Eposi Grund (Fig. 1, c) in the Sabouraud and Czapek medium is 2.3 and 3 points, respectively (Fig. 5, 6). These values are 1.3-1.35 times higher compared to the values on the $14^{\text {th }}$ day after the infection and 2.3 and 1.5 times higher compared to the to the values on the $7^{\text {th }}$ day after infection. In both media and on both film formers, no delay in the growth of the mycelium of the fungus Aspergillus niger was observed.

In the alkyd film former of the PF-115P paint, on the $21^{\text {st }}$ day, the lesion level in the Sabouraud media remains at the level of the one observed on the $14^{\text {th }}$ day, i.e. 3.7 points $($ Fig. 2, $\boldsymbol{c}, \mathbf{5}, \mathbf{6}$ ), which is 1.1 times higher than in the previous period. No zones of mycelium growth delay were observed in both media.

In the pentaphthalic film former of the Silica paint, modified with silicone, on the $21^{\text {st }}$ day from the moment of infection (Fig. 3, c, 5, 6) in the Sabouraud medium, the lesion level is 4 points, which is 1.1 times higher than in the previous period. In the Czapek medium, the lesion level is 3 points and remains at the level of the previous induction period.

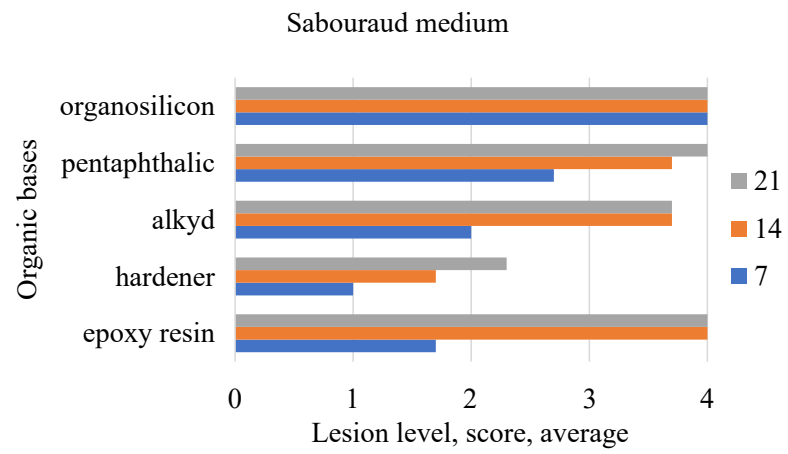

Fig. 5. The level of infection by the fungus Aspergillus niger of organic paint base in the of Sabouraud medium after 7, 14 and 21 days from the beginning of infection

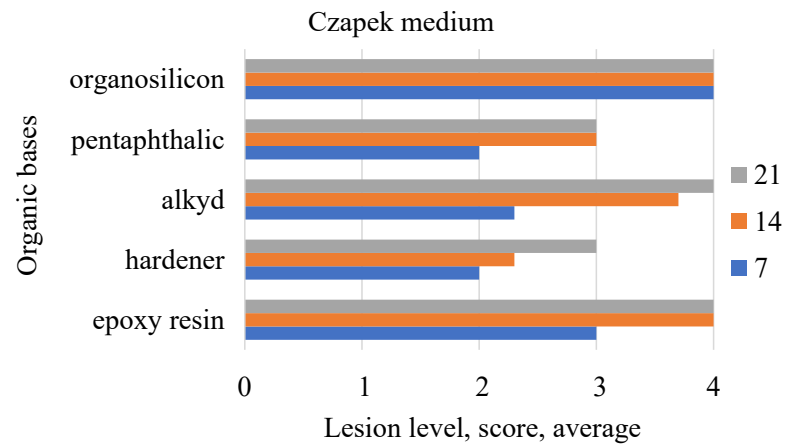

Fig. 6. The level of infection by the fungus Aspergillus niger of organic base paint in the of Czapek medium after 7, 14 and 21 days from the beginning of infection

On the $21^{\text {st }}$ day from the moment of infection, the organosilicon film former of the $\mathrm{KO}-814 \mathrm{~K}$ paint is completely infected. The lesion level is maximum, the value of which is 4 points (Fig. 4, $\boldsymbol{c}, \mathbf{5}, \mathbf{6})$. No zones of delayed growth of the mycelium were noted.

Results regarding the biostability of film formers of varnish-and-paint materials against the action of wood-destroying mold fungi in real time were obtained. The level of damage of the film formers caused by the mycelium of the mold fungus was visually assessed. The investigations are characterized by limitations that do not allow for making calculations related to the growth rate of the mold fungus population and the determination of the lesion level of the varnish-and-paint film formers at the macro level. 
The results obtained are interesting from a practical point of view. The limitations that are inherent in the research method chosen in the work are visualization and competence in carrying out work in this direction and are limited by the requirements of standards DSTU EN 15457:2015 [REF] (EN 15457:2014, IDT), ISO/IEC 17025:2017 [REF] and DSTU EN 1275:2004 [REF] (EN 1275:1997, IDT).

The manifestation of the destructive activity of micromycetes of the genus Aspergillus in relation to the considered organic bases occurs in the $\mathrm{pH}$ range from 4 to 6.7 , the values of which are optimal for the growth and development of molds, which is confirmed by the data of works [19, 20].

From a biochemical point of view, the high destructive activity of micromycetes of the genus Aspergillus is explained by a powerful enzymatic apparatus, manifested in the release of citric, gluconic and oxalic acids. The damaging effect of these acids on the organic bases of paints and varnishes considered in the work is manifested even at rather low concentrations of $0.09-0.4 \%[19,20]$. The destructive effect is also exerted by the $\mathrm{pH}$ of the bases themselves, which ranges from 4 to 6.7. These $\mathrm{pH}$ values are optimal for the development of micromycetes of the genus Aspergillus, while the upper limit of their vital activity lies in the range of $\mathrm{pH} 7.0-7.5[19,20]$.

From a scientific point of view, the development of this study can be carried out through the implementation of a mathematical model for assessing the biological damage to wood in natural conditions. Difficulties that may arise will be in assessing UV doses as well as moisture saturation of the samples. In the process of performing research, it is necessary to focus on maintaining the bearing capacity of structural elements made of wood. The model can be realized analytically using the apparatus of fuzzy mathematics or by visualization in the ANSYS mathematical environment (Ansys Inc., USA).

\section{Conclusions}

As a result of the investigation, the biostability of organic film formers of varnish-and-paint materials, intended for wood dyeing, to the effect of the fungus Aspergillus niger, was studied. It was shown that with an increase in the exposure time, an increase of the level of damage (lesion level) of organic film formers of paints by the mycelium of the fungus occurs in the Sabouraud and Czapek media. Further, no zones of mycelial growth delay were observed. The organic film formers were most intensively affected by the fungus both after 7 days of exposure, and at later time, reaching the maximum values of lesions, i.e. 4 points. According to the degree of stability, the organic film formers can be ranked in the following order: pentaphthalic>epoxy (Eposi Grund)>alkyd $>$ organosilicon; the above-mentioned film formers show the greatest resistance (stability) in the Czapek medium, the average level of damage (lesion) is 3.7 points.

The practical applicability of the results obtained is as follows, namely: before painting wood and products based on it, it is possible to inspect the products, highlight areas with contamination and treat them with impregnation or primer containing a film fungicide. After that, depending on the operating conditions, paint the wood and products based on it with paints that are most resistant to the influence of the fungus Aspergillus niger.

\section{Acknowledgment}

The work was carried out within the framework of the budgetary theme of BSTU No. SB 12-16 «Research and development of resource-saving technologies of sawing, hydrothermal treatment and protection of wood» section 2 «Research of processes and development of resource-saving technologies for wood protection, creation of new highly effective, environmentally friendly wood preservatives»».

\section{References}

[1] Stranger-Johannessen, M., Norgaard, E. (1991). Deterioration of anti-corrosive paints by extracellular microbial products. International Biodeterioration, 27 (2), 157-162. doi: https://doi.org/10.1016/0265-3036(91)90007-e

[2] Aspergillus niger. MYCOBANK Database. Available at: https://www.mycobank.org/page/Name\%20details\%20page/name/ Aspergillus\%20niger

[3] Wang, X. W., Houbraken, J., Groenewald, J. Z., Meijer, M., Andersen, B., Nielsen, K. F. et. al. (2016). Diversity and taxonomy of Chaetomium and chaetomium-like fungi from indoor environments. Studies in Mycology, 84, 145-224. doi: https://doi.org/ 10.1016/j.simyco.2016.11.005 
[4] Rai, M., Bridge, P. D. (Eds.) (2009). Applied Mycology. CABI, 336. doi: https://doi.org/10.1079/9781845935344.0000

[5] Stoye, D., Freitag, W. (Eds.) (1998). Paints, coatings and solvents. John Wiley \& Sons. doi: https://doi.org/10.1002/9783527611867

[6] Schultz, T. P., Nicholas, D. D. (2004). Solid Wood Processing | Protection of Wood against Biodeterioration. Encyclopedia of Forest Sciences, 1274-1282. doi: https://doi.org/10.1016/b0-12-145160-7/00048-x

[7] Arreche, R., Vázquez, P. (2020). Green biocides to control biodeterioration in materials science and the example of preserving World Heritage Monuments. Current Opinion in Green and Sustainable Chemistry, 25, 100359. doi: https://doi.org/10.1016/ j.cogsc.2020.100359

[8] Sabadaha, E. N., Prokopchuk, N. R., Goncharova, I. A. (2010). Vliyanie metabolitov gribov na fiziko-mehanicheskie svoystva lakokrasochnyh pokrytiy. Trudy BGTU. Seriya IV. Himiya, tehnologiya organicheskih veschestv i biotehnologiya, XVIII, 306-309. Available at: https://cyberleninka.ru/article/n/vliyanie-metabolitov-gribov-na-fiziko-mehanicheskie-svoystvalakokrasochnyh-pokrytiy

[9] Gorban, M. V., Yampolskaya, T. D. (2012). Physiological aspects of synthetic and natural polymers destruction by collection and native strains of micromycetes. Izvestiya Samarskogo nauchnogo centra Rossiyskoy akademii nauk, 14 (1 (9)), $2206-2210$. Available at: https://cyberleninka.ru/article/n/fiziologicheskie-aspekty-destruktsii-sinteticheskih-i-prirodnyh-polimerovkollektsionnymi-i-aborigennymi-shtammami-mikromitsetov

[10] Biodeterioration of materials. Microbiological and allied aspects: Proceedings of the 1st International Biodeterioration Symposium, Southampton, 9th-14th September, 1968. Edited by A. H. Walters and J. J. Elphick. Elsevier Publishing Co., Ltd., London, 1968. pp. $x+740.250$ s (1969). Food and Cosmetics Toxicology. 7, 638-639. doi: https://doi.org/10.1016/s0015-6264(69)80468-2

[11] Watkinson, S. C., Eastwood, D. C. (2012). Serpula lacrymans, Wood and Buildings. Advances in Applied Microbiology, 121-149. doi: https://doi.org/10.1016/b978-0-12-394805-2.00005-1

[12] Moncmanová, A. (2007). Environmental factors that influence the deterioration of materials. WIT Transactions on State of the Art in Science and Engineering, 1-25. doi: https://doi.org/10.2495/978-1-84564-032-3/01

[13] Sabadaha, E. N., Prokopchuk, N. R., Shutova, A. L. (2016). The environmental impact reduction principles of bioprotective paintwork material during the wood surface paint. Trudy BGTU, 4, 225-231. Available at: https://elib.belstu.by/ handle/123456789/18560

[14] Gámez-Espinosa, E., Bellotti, N., Deyá, C., Cabello, M. (2020). Mycological studies as a tool to improve the control of building materials biodeterioration. Journal of Building Engineering, 32, 101738. doi: https://doi.org/10.1016/j.jobe.2020.101738

[15] Allsopp, D., Seal, K. J., Gaylarde, Ch. C. (2004). Introduction to biodeterioration. Cambridge University Press. doi: https://doi.org/ 10.1017/cbo9780511617065

[16] Gillatt, J., Julian, K., Brett, K., Goldbach, M., Grohmann, J., Heer, B. et. al. (2015). The microbial resistance of polymer dispersions and the efficacy of polymer dispersion biocides - A statistically validated method. International Biodeterioration \& Biodegradation, 104, 32-37. doi: https://doi.org/10.1016/j.ibiod.2015.04.028

[17] De Souza, A., Gaylarde, C. C. (2002). Biodeterioration of varnished wood with and without biocide: implications for standard test methods. International Biodeterioration \& Biodegradation, 49 (1), 21-25. doi: https://doi.org/10.1016/s0964-8305(01)00102-0

[18] Grant, C., Wright, I. C., Springle, W. R., Greenhalgh, M. (1993). Collaborative investigations of laboratory test methods for evaluation of the growth of pink yeasts on paint films. International Biodeterioration \& Biodegradation, 32 (4), $279-288$. doi: https://doi.org/10.1016/0964-8305(93)90030-6

[19] Stroganov, V. F., Sagadeev, E. V. (2014). Vvedenie v biopovrezhdenie stroitel'nyh materialov. Kazan': Izd-vo KGASU, 200. Available at: https://search.rsl.ru/ru/record/01008008996

[20] Stroganov, V. F., Sagadeev, E. V. (2018). Biopovrezhdenie stroitel'nyh materialov. Kazan': Izd-vo KGASU, 61. Available at: https://www.kgasu.ru/upload/iblock/a63/Biopovrezhdenie-stroitelnykh-materialov-Stroganov-V.F.-Sagadeev-E.V..pdf

How to cite: Guzii, S., Bazhelka, I., Kanavalava, A. (2021). Research of the biostability of organic bases of paints for wood. EUREKA: Physics and Engineering, 6, 11-18. doi: https://doi.org/10.21303/2461-4262.2021.002142 